This journal is the official publication of Bangladesh Society of Physiologists (BSP)

Web URL: www.banglajol.info/index.php/JBSP

Abstracted /indexed in Index Copernicus, Director of Open Access Journal, HINARI Index Medicus for South East Asia Region, Google Scholar, 12OR, infobse index, Open J gate, Cite factor, Scientific indexing services

pISSN-1983-1213; e-ISSN-2219-7508

Article

Article information:

Received: $20^{\text {th }}$ October 2020

Accepted: $10^{\text {th }}$ February 2021

DOI: https://doi.org/10.3329/jbsp.v16i1.54348

Corresponding author:

Dr Manish Kumar Verma, Department of Physiology, Dr Ram Manohar Lohia Institute of Medical sciences, Vibhuti Khand, Gomti Nagar, Lucknow India, Pin 226010, email: drmanish 24@gmail.com, Mobile:+91-9412566505

Cite this article:

Gangwar V, Verma MK, Gangwar RS, John NA, Jasrotia RB. The effect of moderate versus high intensity exercise on heart rate variability in sedentary office workers. J Bangladesh Soc Physiol 2021; 16(1): 16-23

This article is open access licensed under CC BY NC SA which allows readers copy, distribute, display, and perform the work and make derivative works based on it only for noncommercial purposes.

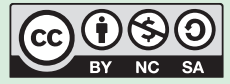

\section{The effect of moderate versus high intensity exercise on heart rate variability in sedentary office workers}

\author{
Vibha Gangwar ${ }^{1}$, Manish Kumar Verma ${ }^{1}$, Ritesh Singh \\ Gangwar $^{2}$, Nitin Ashok John' ${ }^{1}$, Rajani Bala Jasrotia ${ }^{1}$ \\ 1. Department of Physiology, Dr Ram Manohar Lohia Institute of Medical \\ Sciences, Lucknow, India, \\ 2. Department of Cardiology, Rama Medical College, Hospital \& Research \\ Center, Kanpur, India
}

\section{Abstract}

Background: Sedentary behavior is one of the leading modifiable risk factors for cardiovascular disease and all-cause mortality. Physical exercise exerts beneficial physiological effects on cardiovascular fitness. Different grades of physical exercise have different effects on cardiovascular health. Objective: To compare the effect of moderate and high intensity exercise training on heart rate variability (HRV) in sedentary office workers. Methods: This study was conducted on 40 healthy sedentary volunteers aged between 20-40 years of both the genders. Participants were distributed into two groups of 20 subjects each. Subjects of group I and group II performed moderate intensity and high intensity exercise respectively on bicycle ergometer for 12 weeks. Their 5minute ECG recording was done by three channel physiograph, and frequency domain indices of HRV and heart rate (HR) were analyzed and compared before and after exercise training. Their blood pressure was also recorded and compared before and after exercise training. Independent sample t-test and paired sample ttest were used for statistical analysis. Results: HF, systolic and diastolic blood pressure reduced significantly after exercise in group II ( $\mathrm{p}=0.015,0.005$, and 0.015 respectively) while $\mathrm{HR}$ and LF/HF ratio reduced in both group I and group II ( $\mathrm{p}=0.000$ for $\mathrm{HR}$, and $0.034,0.001$ for $\mathrm{LF} / \mathrm{HF}$ ). The decrease in HR was greater after high intensity exercise than moderate intensity exercise $(p=0.025)$. Conclusion: Parasympathetic activity improves after moderate and high intensity exercise but improvement is more after high intensity exercise training. Therefore, high intensity exercise training is more beneficial than moderate intensity exercise training.

Keywords: moderate-intensity exercise, high-intensity exercise, heart rate variability, heart rate, blood pressure 
Introduction

$\mathbf{S}$ edentary behavior is defined as any working behavior with energy expenditure 1.5 metabolic equivalent of task (METS) ${ }^{1}$. In the present-day world, the innovation in technology and profound use of computers in all office tasks has led to the increase in sedentary lifestyle and more time being spent sitting before desk. Adults spend about $51-68 \%$ of daily waking hours in sedentary $\operatorname{activities}^{2,3}$.

Sedentary lifestyle is a major risk factor for congestive heart failure, stroke, obesity and hypertension ${ }^{4}$.Cardiovascular system is regulated by autonomic nervous system including sympathetic \& parasympathetic nervous system. Balance between these two components of autonomic nervous system is important for adequate functioning of cardiovascular system. Risk factors for cardiovascular diseases have a negative impact on autonomic functions ${ }^{5}$.

One of the important markers of autonomic functions is heart rate variability (HRV) which is negatively associated with cardiovascular risk factors such as physical inactivity ${ }^{6}$. Low HRV is related to increased risk of ventricular arrhythmias and coronary artery diseases ${ }^{7-10}$.

Interaction between sympathetic and parasympathetic nervous system causes variation in beat-to-beat interval in ECG. Reduced HRV indicates decreased parasympathetic activity or increased sympathetic activity. HRV can be analyzed by time and frequency domain methods. Short-term recording of frequency domain parameters is useful for analysis of sympathovagal balance ${ }^{11}$. High frequency power (HF) indicates parasympathetic activity while low frequency power (LF) indicates combination of both sympathetic and parasympathetic activity $^{12}$.

HRV is influenced by duration and intensity of exercise. A short observational report showed that vigorous physical activity significantly predicted greater HRV in young adults ${ }^{13}$. Some other studies compared the effect of moderate and high intensity exercise on various other physiological mechanisms ${ }^{14-17}$. All these previous studies were based on self -reported level of physical exercise which may vary from person to person. These facts gave us impetus to verify the effect of moderate and high intensity exercise training on heart rate variability.

\section{Methods}

This study was conducted in the department of Physiology, Dr Ram Manohar Lohia Institute of Medical Sciences, Lucknow India. The study was approved by ethics committee of Dr Ram Manohar Lohia Institute of medical Sciences, Lucknow.

\section{Subjects}

Forty healthy sedentary office professionals of both the genders aged between $20-40$ years were selected randomly to participate in the study. Their participation was voluntary and a written consent was taken from all the participants. The study was done as per Helsinki Guidelines.

A detailed history was taken from all the participants to assess their physical and psychological health to exclude any clinical abnormality. The subjects not engaged in any exercise programme or doing low intensity exercise (heart rate $<50 \%$ of $\mathrm{HR}_{\max }$ ) or sports activity for $<20 \mathrm{~min}$ in a week were included in study $^{18}$. Exclusion criteria were a history of smoking, athletic activity, anemia, any systemic disease, depression, anxiety, previous surgery, and medication known to have an impact on autonomic function.

All the participants were instructed to avoid tea, coffee, smoking, alcohol and additional physical activity for at least two days prior to the exercise session and not to have any feed during last two hours prior to the exercise sessions. They were randomly divided into two groups of 20 subjects each to perform exercise training on bicycle 
ergometer (Avon Cycles Ltd, Ludhiana, India) for 12 weeks periods.

\section{Exercise protocol}

Participants of moderate intensity exercise group (group I) performed steady state cycling at heart rate of $50 \%-74 \%$ of $\mathrm{HR}_{\max }$ for a duration of 40 minutes, 5 days per week. Participants of high intensity exercise group (group II) performed 8 sec sprints cycling at a heart rate of $75 \%-84 \%$ of $\mathrm{HR}_{\text {max }}$ followed by 12 seconds of low intensity cycling for a duration of 20 minutes for 3 times per week ${ }^{19}$. All the exercise sessions were conducted in the Department of Physiology, Dr Ram Manohar Lohia Institute of Medical Sciences Lucknow under strict supervision.

\section{Measurement of HRV}

Measurement of HRV was conducted in quiet autonomic function lab with soothing light and comfortable temperature being maintained in the Department of Physiology and analysed according to the standards proposed by Task force of the European Society of Cardiology and the North American Society of Pacing and Electrophysiology ${ }^{12}$. Subjects were instructed to take nothing by mouth 2 hours prior to the recording. After the explanation of procedure they were asked to take rest in the quiet autonomic function lab in supine position for 30 minutes to allow reduction of heart rate to a minimum level. Any electronic gadget or metal object, which could interfere with the recording, was removed. HRV was recorded by ECG lead II for 5 minutes at a frequency of 500 samples per second by three channel Physiograph (AD instruments South Asia (India) Pvt Ltd, New Delhi, India). All the recordings were done at a fixed time of the day (4.00 PM) to rule out diurnal variation. Recording of HRV was done two times, before beginning and after completion of exercise training of 12 weeks.

Frequency-domain parameters of HRV were analysed by spectral analysis using software LABCHART PROV8.1.8 software WITH HRV MODULE V.2.0.3. Low frequency band (LF), high frequency band (HF), total power and LF/ HF ratio were taken into consideration.

Weight and height, blood pressure and HR were also measured following the HRV recording.

\section{Statistical analysis}

Statistical analysis was performed using software SPSS version 21.0 (IBM Corp., Armonk, NY, USA). Data were represented as mean \pm standard deviation (SD) of mean. Comparisons of mean values of demographic characteristics between the two groups were done by independent sample t-test. Frequency-domain parameters of HRV, $\mathrm{HR}$, systolic blood pressure (SBP), and diastolic blood pressure (DBP) of both the groups before and after exercise were compared by paired sample t-test. Post exercise parameters of group I and II were also compared by independent sample t-test. p-value $<0.05$ was considered statistically significant.

\section{Results}

Forty healthy sedentary subjects (25 males and 15 females) took part in the study. They were randomly distributed in two groups of 20 subjects each. The subjects of group I and group II performed moderate and high intensity exercise, respectively. (Table I)

Table 1: Gender distribution of Participants

\begin{tabular}{lccc}
\hline Gender & Group I & Group II & Total \\
\hline Male & 11 & 14 & 25 \\
Female & 9 & 6 & 15 \\
\hline Total & 20 & 20 & 20 \\
\hline Group I =Moderate intensity exercise group, Group \\
II = High intensity exercise group
\end{tabular}

The mean age of the subjects in group I and group II was $37.2 \pm 12.18$ years \& $36.87 \pm 9.71$ years respectively. The mean body mass index (BMI) of the participants of both the groups was within normal range $\left(<25 \mathrm{~kg} / \mathrm{m}^{2}\right)$. Baseline characteristics of the participants in both the group were similar $(\mathrm{p}>0.05)$ (Table II).

Volume 16 No. 1 June 2021: 16-23 
Table II: Characteristics of Participants

\begin{tabular}{lccc}
\hline Variable & Group I (Mean $\pm \mathrm{SD})$ & Group II (Mean $\pm \mathrm{SD})$ & ${ }^{1} \mathrm{P}$ \\
& $\mathrm{N}=20$ & $\mathrm{~N}=20$ & value \\
\hline Age (years) & $37.2 \pm 12.18$ & $36.87 \pm 9.71$ & 0.94 \\
Weight $(\mathrm{kg})$ & $65.33 \pm 14.54$ & $64.73 \pm 11.76$ & 0.94 \\
Height $(\mathrm{cm})$ & $164.4 \pm 6.75$ & $166.47 \pm 8.12$ & 0.96 \\
Body mass index $\left(\mathrm{kg} / \mathrm{m}^{2}\right)$ & $24.18 \pm 4.79$ & $24.19 \pm 3.31$ & 0.99 \\
\hline
\end{tabular}

Data are represented as mean $\pm \mathrm{SD}$, Statistical analysis was done by independent sample ' $t$ ' test, Group I = Moderate intensity exercise group, Group II = High intensity exercise group

\section{HRV parameters before exercise training}

The average total power of the participants of both the groups was normal. The average LF in group I and group II was $403.26 \mathrm{~ms}^{2}$ and 426.5 $\mathrm{ms}^{2}$ respectively. The average HF in group I and II was $266.12 \mathrm{~ms}^{2}$ and $498.49 \mathrm{~ms}^{2}$ respectively, showing low parasympathetic activity. The average LF/HF ratio in group I was 2.90 showing abnormal sympathovagal balance while in group II it was 1.6 (Table III).

\section{Changes in HRV after exercise training}

Total power and LF failed to improve significantly after 12 weeks of exercise training in both the groups ( $p=0.703$ and 0.398 , respectively). LF/HF ratio reduced significantly after moderate and high, both type of exercise trainings indicating improvement in sympathovagal balance $(\mathrm{p}=0.034$ and 0.001 , respectively). HF increased significantly only after high intensity exercise showing improvement in parasympathetic activity $(\mathrm{P}=0.015)$ which was not seen after moderate intensity exercise $(p=0.269)$. Heart rate decreased significantly in both the groups after exercise ( $p$ $=0.000$ ) but decrease in systolic and diastolic blood pressure was significant only in group II $(\mathrm{p}=0.005,0.015$ respectively). (Table III)

Table IV shows comparison of parameters of HRV after exercise training of 12 weeks in group I and II. There was no significant difference in post exercise LF, HF, total power, LF/HF, and blood pressure in both the groups $(p>0.05)$ but heart rate was significantly lower in group II than group I $(p=0.025)$.

Table III: Comparison of HRV before and after exercise in subjects of group I and group II

\begin{tabular}{lcccccccc}
\hline Parameter & \multicolumn{3}{c}{ Group I $(\mathrm{N}=20)$} & & \multicolumn{3}{c}{ Group II $(\mathrm{N}=20)$} \\
\cline { 2 - 3 } & Before Exercise & After exercise & & ${ }^{1}$ p-value & & Before Exercise & After exercise & ${ }^{1}$ p-value \\
\hline Total Power $\left(\mathrm{ms}^{2}\right)$ & $1209.95 \pm 1247.61$ & $1362.28 \pm 1717.90$ & 0.177 & & $1482.02 \pm 1221.96$ & $1563.13 \pm 922.75$ & 0.703 \\
LF $\left(\mathrm{ms}^{2}\right)$ & $403.26 \pm 497.77$ & $409.56 \pm 271.23$ & 0.935 & & $426.5 \pm 308.37$ & $509.70 \pm 287.87$ & 0.398 \\
HF $\left(\mathrm{ms}^{2}\right)$ & $266.12 \pm 246.73$ & $578.65 \pm 226.89$ & 0.269 & $498.49 \pm 815.52$ & $908.39 \pm 613.97$ & $0.015^{*}$ \\
LF/HF & $2.90 \pm 3.55$ & $1.53 \pm 0.16$ & $0.034^{*}$ & $1.60 \pm 1.05$ & $0.62 \pm 0.14$ & $0.001^{*}$ \\
Hear rate (beats/minute) & 83.6 & 77.13 & $0.000^{*}$ & & 85.73 & 69.93 & $0.000^{*}$ \\
SBP(mm Hg) & 125 & 120.94 & 0.165 & & 122.47 & 114.26 & $0.005^{*}$ \\
DBP $(\mathrm{mm} \mathrm{Hg})$ & 80.67 & 79.2 & 0.312 & & 83.73 & 76.6 & $0.015^{*}$ \\
\hline
\end{tabular}

Data are represented as mean $\pm \mathrm{SD}$, statistical test used was paired sample ' $\mathrm{t}$ ' test

Group I = Moderate intensity exercise group, Group II = High intensity exercise group

$\mathrm{LF}=$ Low frequency, $\mathrm{HF}=$ High Frequency, $\mathrm{SBP}=$ systolic blood pressure, $\mathrm{DBP}=$ diastolic blood pressure

*=significant difference in between group I \& II ( $<<0.05$ significant)

Volume 16 No. 1 June 2021: 16-23 
Table IV: Comparison of HRV after exercise in subjects of group I and group II

\begin{tabular}{lccc}
\hline Parameter & Group I & Group II & $\begin{array}{c}{ }^{\mathrm{p}} \text { - } \\
\text { value }\end{array}$ \\
\hline Total Power $\left(\mathrm{ms}^{2}\right)$ & $1362.28 \pm 1717.90$ & $\mathrm{~N}=20$ & 0.183 \\
LF $\left(\mathrm{ms}^{2}\right)$ & $409.56 \pm 271.23$ & $1563.13 \pm 922.75$ & 0.307 \\
HF $\left(\mathrm{ms}^{2}\right)$ & $578.65 \pm 226.89$ & $509.70 \pm 287.87$ & 0.245 \\
LF/HF & $1.53 \pm 0.16$ & $908.39 \pm 613.97$ & 0.271 \\
Hear rate(beats/min) & 77.13 & $0.62 \pm 0.14$ & $0.025^{*}$ \\
SBP $(\mathrm{mm} \mathrm{Hg})$ & 120.94 & 69.93 & 0.091 \\
DBP $(\mathrm{mmHg})$ & 79.2 & 114.26 & 0.216 \\
\hline
\end{tabular}

Data are represented as mean $\pm \mathrm{SD}$, Statistical analysis was done by independent sample ' $t$ ' test Group I = Moderate intensity exercise group, Group II = High intensity exercise group

$\mathrm{LF}=$ Low frequency, $\mathrm{HF}=$ High Frequency, $\mathrm{SBP}=$ systolic blood pressure, $\mathrm{DBP}=$ diastolic blood pressure *=significant difference in between group I \& II ( $\mathrm{p}<0.05$ significant)

\section{Discussion}

The level of physical activity has an important role in cardiovascular health. Regular exercise is very important to keep cardiovascular system healthy. Measurement of HRV is a non-invasive method to investigate cardiac autonomicfunctions ${ }^{20}$. However, during interpretation of these functions, the key factor, which has to be considered, is how the intensity of exercise may affect the response. Therefore, the purpose of this research was to investigate the effect of different intensities of exercise, i.e. moderate and high, on autonomic functions in sedentary office workers.

As the vagal activity is the major contributor of HF component of $\mathrm{HRV}^{21}$, our results showed low parasympathetic activity in the participants despite normal BMI. BMI is an indicator of general obesity and some studies showed that central obesity is a better discriminator of cardiac autonomic functions than general obesity ${ }^{22}$. We did not measure WHR which is a parameter of central obesity. LF/HF ratio estimates the ratio between sympathetic nervous system and parasympathetic nervous system activity. Low LF/HF ratio indicates parasympathetic dominance while a high $\mathrm{LF} / \mathrm{HF}$ ratio reflects sympathetic dominance ${ }^{23}$. One previous study demonstrated that a sedentary lifestyle counters the benefits of being a normal weight in terms of heart disease risk ${ }^{24}$.In our study, baseline LH/ HF ratio was high, reflecting high sympathetic activity. These results are supported by another study which also found higher LF/HF ratio in sedentary women ${ }^{25}$.

$\mathrm{LF} / \mathrm{HF}$ ratio is an indicator of sympathovagal balance $^{12}$. Decreased LF/HF ratio indicates increased parasympathetic activity. Exercise modulates sympathovagal balance by increasing vagal while decreasing sympathetic activity. Our study also supported this fact by showing significant decrease in LF/HF ratio in both the groups Decrease was greater after high intensity exercise training than moderate intensity exercise $\&$ it was significant.

HF increased significantly after high intensity exercise in our study. HF increased after moderate intensity exercise too, but it was not significant. These results are comparable to the reports of higher HF with vigorous activity but not with moderate activity ${ }^{26}$. The post exercise increased parasympathetic activity in this study may be due to improved baroreflex sensitivity after exercise ${ }^{27}$.In addition, this study ${ }^{26}$ also

Volume 16 No. 1 June 2021: 16-23 
observed increased LF after moderate and vigorous exercises which contradicts to our finding of no significant change in LF after both grades of exercise. They concluded it as overall increase in parasympathetic activity but they were not able to explain whether an increase in parasympathetic activity and decrease in sympathetic activity are responsible for an increase in low frequency power. Another similar study found no significant change in vagal outflow in sedentary persons after any type of exercise $^{28}$. We also found a significant decrease in LF/HF ratio after both moderate and high intensity exercise reflecting improvement in sympathovagal balance. This effect is similar to the observation by Alansare A et al after high intensity exercise but they failed to show significant improvement in LF/HF ratio after moderate intensity exercise ${ }^{29}$. However, they did not find significant change in LF and HF. They concluded that high intensity training programme is superior to moderate intensity exercise programme in improving HRV.

In most of the previous studies ${ }^{13,26}$, the physical activity was assessed by self-reported questionnaire while in this study participants performed exercise under supervision in the physiology lab on bicycle ergometer. The participants were divided into two groups. Subjects of group I performed moderate intensity exercise by cycling at heart rate of $50 \%-74 \%$ of a heart rate maximum reserve for a duration of 40 minutes, 5 days per week. Subjects of group II performed high intensity exercise by $8 \mathrm{sec}$ sprints cycling at a heart rate of $75 \%-84 \%$ of heart rate maximum reserve followed by 12 seconds of low intensity cycling for a duration of 20 minutes for 3 times per week. The HRV of the participants was measured after performing exercise for 12 weeks duration. One previous study also practiced similar exercise protocol to study the effect of exercise intensity on body composition in overweight and obese individuals ${ }^{19}$. However, another study compared the effect of exercise intensity on HRV by involving the participants in exercise training, but its sample size was only thirteen too small for conclusion $^{29}$. Previous studies did not take the psychological factors such as depression in consideration ${ }^{13}$ while we excluded these factors from our study.

Regular physical exercise is an effective nonpharmacological approach to improve blood pressure $^{30}$. In this context, our study showed decrease in SBP and DBP after 12 weeks of high intensity exercise programme. Previous studies found only decrease in SBP after high intensity and moderate intensity exercise sessions ${ }^{29,31}$. This improvement in blood pressure following exercise programmes may be attributed to improved vascular functions and diameter ${ }^{32}$. Our study also demonstrated decrease in heart rate after both type of exercise trainings but decrease was more after high intensity exercise training. Similar results were also found in another study ${ }^{33}$.

There are certain limitations of our study, which should be noted. The duration of intervention was short although it was similar to those in the earlier randomized studies ${ }^{34}$. We did not control the respiration of subjects during recording of HRV. Respiratory rhythm can affect the frequency domain parameters ${ }^{35}$. We included participants of age group 20-40years in our study. The results might differ in older or younger subjects ${ }^{36}$.

\section{Conclusion}

This study suggested that high intensity exercise is more effective in improving sympathovagal balance and heart rate in sedentary people. This study also revealed that cardiac autonomic activity may be abnormal despite normal BMI. High intensity exercise requires less duration to produce the changes as compared to the moderate intensity exercise of extended duration. Therefore, we believe that our results will contribute in making exercise protocols more effective in the current scenario. Further studies 
with greater sample size and controlled respiratory rhythm are needed to confirm this hypothesis.

Conflict of interest The authors have no conflict of interest relevant to this article.

\section{Financial Support NA}

\section{Acknowledgement}

We are thankful to the office staff and colleagues for their co-operation. We are also thankful to the Mr Prithvi Kumar, statistician for helping us in doing statistical analysis.

\section{References}

1. Owen N, Sugiyama T, Eakin EE, Gardiner PA, Trembly MS, Sallis JF. Adults' sedentary behavior determinants and interventions. Am J Prev Med. 2011; 41(2): 189196.

2. Thorp AA, Owen N, Neuhaus M, Dunstan DW. Sedentary behaviours and subsequent health outcomes in adults: a systematic review of longitudinal studies, 1996-2011. Am J Prev Med. 2011; 41(2): 207-215.

3. Proper KI, Singh AS, van Mechelen W, Chinapaw MJ. Sedentary behaviors and health outcomes among adults: a systematic review of prospective studies. Am J Prev Med. 2011; 40(2):174-182.

4. Warren TY, Barry V, Hooker SP, Sui X, Church TS, Blair SN. Sedentary behaviour increases risk of cardiovascular disease mortality in men. Med Sci Sports Exerc. 2010; 42(5): 879-885.

5. Curtis BM, O'Keefe JH. Autonomic tone as a cardiovascular risk factor: the dangers of chronic fight or flight. Mayo Clin Proc. 2002; 77(1): 45-54.

6. Thayer JF, Yamamoto SS, Brosschot JF. The relationship of autonomic imbalance, heart rate variability and cardiovascular disease risk factors.Int J Cardiol. 2010;141(2):122-13.

7. Tsuji H, Larson MG, Venditti FJ Jr, Manders ES Evans JC, Feldman, Lavy D. Impact of reduced heart rate variability on risk for cardiac events. The Framingham Heart Study. Circulation. 1996; 94(11):28502855.

8. Algra A, Tijssen JG, Roelandt JR, Pool J, Lubsen J. Heart rate variability from 24-hour electrocardiography and the 2-year risk for sudden death. Circulation. 1993; 88(1):180-185.
9. Dekker JM, Schouten EG, Klootwijk P, Pool J, Swenne CA, Kromhout D. Heart rate variability from short electrocardiographic recordings predicts mortality from all causes in middle-aged and elderly men. The Zutphen Study. Am J Epidemiol.1997;145(10): 899908.

10. Liao D, Cai J, Rosamond WD, Barnes RW, Hutchinson RG, Whitsel EA, Rautaharju P, Heiss G. Cardiac autonomic function and incident coronary heart disease: a population-based case-cohort study. The ARIC Study. Atherosclerosis Risk in Communities Study. Am J Epidemiol. 1997; 145(8): 696-706.

11. Metelka R. Heart rate variability-current diagnosis of the cardiac autonomic neuropathy. A review. Biomed Pap Med Fac Univ Palacky Olomouc Czech Repub. 2014;158(3): 327-338.

12. Task force of the European Society of cardiology and the north American society of pacing and electrophysiology. Heart rate variabilty standards of measurements, physiological interpretation, and clinical use. Eur Heart J. 1996; 17: 354-381.

13. May R, McBerty V, Zaky A, Gianotti M. Vigorous physical activity predicts higher heart rate variabilty among younger adults. J Physiol Anthropol. 2017; 36: 24.

14. Henriksson J, Reitman JS. Quantitative measures of enzyme activities in type I and type II muscle fibres of man after training. Acta Physiol Scand. 1976; 97(3): 392-397.

15. Saltin B, Nazar K, Costill DL, Stein E, Jansson E, Essen $\mathrm{B}$, Gollnick D. The nature of the training response; peripheral and central adaptations of one-legged exercise. Acta Physiol Scand. 1976; 96(3): 289-305.

16. Burgomaster KA, Howarth KR, Phillips SM, Rakobowchuk M, Macdonald MJ, McGee SL, Gibala MJ. Similar metabolic adaptations during exercise after low volume sprint interval and traditional endurance training in humans. J Physiol. 2008; 586(1): 151-160.

17. Burgomaster KA, Heigenhauser GJ \& Gibal MJ. Effect of short-term sprint interval training on human skeletal muscle carbohydrate metabolism during exercise and time-trail performance. J Appl Physiol (1985). 2006; 100(6): 2041-2047.

18. Nystoriak MA, Bhatnagar A. Cardiovascular Effects and Benefits of Exercise. Font Cardiovasc Med. 2018; 5: 135 .

19. Umangeshwari K, Dhanlakshmi Y, Karthik S, John NA, Sultana R. Effect of exercise intensity on body

Volume 16 No. 1 June 2021: 16-23 
composition in overweight and obese individuals. Indian J Physiol Pharmacol. 2017; 61(1): 58-64.

20. Michael S, Graham KS, Davis GM OAM. Cardiac Autonomic Responses during Exercise and Postexercise Recovery Using Heart Rate Variability and Systolic Time Intervals-A Review. Front. Physiol. 2017; 8: 301.

21. Laborde S, Mosley E, Thayer JF. Heart rate variability and vagal tone in psychophysiological researchrecommendations for experimental planning, data analysis and data reporting. Front Psychol. 2017; 8:213.

22. Farah BQ, Prado WL, Tenorio TR, Ritti-Dias RM. Heart rate variability and its relationship with central and general obesity in obese normotensive adolescents. Einstein (Sao Paulo). 2013; 11(3): 285-290.

23. Shaffer F, Ginsberg JP. An Overview of Heart Rate Variabilty Metrics and Norms. Front Public Health. 2017; 5: 258 .

24. Mainous AG 3rd, Tanner RJ, Rahmanian KP, Jo A, Carek PJ. Effect of Sedentary Lifestyle on Cardiovascular Disease Risk Among Healthy Adults with Body Mass Indexes 18.5 to $29.9 \mathrm{~kg} / \mathrm{m}^{2}$. Am J Cardiol. 2019; 123(5): 764-768.

25. Zaffalon Junior JR, Viana AO, de Melo GEL, De Angelis $\mathrm{K}$. The impact of sedentarism on heart rate variability (HRV) at rest and in response to mental stress in young women. Physiol Rep. 2018; 6(18): e13873.

26. Rennie KL, Hemingway H, Kumari M, Brunner E, Malik M, Marmot M. Effect of moderate and vigorous physical activity on heart rate variability in a British study of civil servants. Am J Epidemiol. 2003;158(2):135-143.

27. Monahan KD, Dinenno FA, Tanaka H, Clevenger CM, DeSouza CA, Seals DR. Regular aerobic exercise modulates age-associated declines in cardiovagal baroreflex sensitivity in healthy men. J Physiol. 2000; 529 Pt 1(Pt 1): 263-271.
28. Loimaala A, Huikuri H, Oja P, Pasanen M, Vouri I. Controlled 5-mo aerobic training improves heart rate but not heart rate variability or baroreflex sensitivity. J Appl Physiol. 2000; 89(5):1825-1829.

29. Alansare A, Alford K, Lee S, Church T, Jung HC. The Effect of High-Intensity Interval Training vs. ModerateIntensity Continuous Training on Heart Rate Variabilty in Physically Inactive Adults. Int J Environ Res Public Health. 2018; 15(7):1508.

30. Cornelissen VA, Smart NA. Exercise training for blood pressure: A systematic review and meta-analysis. J Am Heart Assoc. 2013;2:1-68.

31. Whyte LJ, Gill JM, Cathcart AJ. Effect of 2 weeks of sprint interval training on health-related outcomes in sedentary overweight/obese men. Metab Clin Exp. 2010; 59:1421-1438.

32. Smith DL, Fernhall B. Advanced Cardiovascular Exercise Physiology.Human Kinetics; Champaign, IL, USA: 2011.

33. Coswig VS, Barbalho M, Raiol R, Vecchio FBD, Remirez-Campillo R, Gentil P. Effect of high vs moderate-intensity intermittent training on functionality, resting heart rate and blood pressure of elderly women. J Transl Med. 2020; 18: 88.

34. Kim J, Park HY, Lim K. Effects of 12 weeks of Combined Exercise on Heart Rate Variabilty and Dynamic Pulmonary Function in Obese and Elderly Korean Women. Iran J Public Health. 2018; 47 (Suppl 1): $74-81$.

35. Tripathi LCKK. Respiration and heart rate variability: a review with special reference to its application in aerospace medicine. Med. Ind J of Aerospace Med. 2004; 48(1): 64-75.

36. Hassan A.E. Heart rate and blood pressure responses to exercise testing in relation to age in healthy men. The Iraqi Postgrad. Med. J. 2009; 1:14-20. 